\title{
Broadband optical absorption measurement of silicon nanowires for photovoltaic solar cell applications
}

\author{
Md Ali Asgar • Mehedhi Hasan • Md Fazlul Huq • \\ Zahid Hasan Mahmood
}

Received: 9 March 2013/Accepted: 4 December 2013/Published online: 28 March 2014

(C) The Author(s) 2014. This article is published with open access at Springerlink.com

\begin{abstract}
The broadband optical absorption properties of silicon nanowire films fabricated by electroless metal deposition technique followed by $\mathrm{HF} / \mathrm{Fe}\left(\mathrm{NO}_{3}\right)_{3}$ solutionbased chemical etching at room temperature on p-type silicon substrates have been measured and found absorption higher than that of the solid thin films of equivalent thickness. The observed behavior is effectively explained by light scattering and light trapping though some of the observed absorption is due to a high density of surface states in the nanowires films. Synthesized structures absorbed more than $82 \%$ of incident radiation in case of $\mathrm{Cu}$-deposited silicon nanowires, whereas for $\mathrm{Ag}$ it was maximum $83 \%$, which is much greater than that of the bulk silicon as they absorbed maximum $43 \%$ of the radiation.
\end{abstract}

M. A. Asgar

Department of Electronics and Communication Engineering, Jatiya Kabi Kazi Nazrul Islam University, Trishal, Mymensingh, Bangladesh

M. Hasan

Department of Electrical and Electronic Engineering, Shahjalal University of Science and Technology, Kumargaon, Sylhet 3114, Bangladesh

M. F. Huq ( $\square)$

Department of Nuclear Engineering, University of Dhaka,

Dhaka 1000, Bangladesh

e-mail: fhuq.apece.du@gmail.com

Z. H. Mahmood

Department of Applied Physics Electronics and Communication Engineering, University of Dhaka, Dhaka 1000, Bangladesh
Keywords Silicon nanowires (SiNWs) Electroless metal deposition (EMD) · Photovoltaic (PV) - Optical absorption
Abbreviations
SiNW Silicon nanowire
EMD Electroless metal deposition
PV Photovoltaic
HF Hydrogen fluride
SEM Scanning electron micrograph
UV Ultra violet

\section{Introduction}

To date, the catastrophic environmental pollution arising from burning fossil fuels has discriminating public concern, and thus the increasing dependence on renewable clean energy alternatively. Amongst the alternative energy sources, solar energy represents one of the most sustainable, environmentally acceptable and technologically promising renewable clean energy sources [1,2]. Since the invention of solar cells in the 1950s [3], the solid-state junction photovoltaic solar cell devices have dominated photovoltaic solar energy converters. The most common material used in solar cells is silicon. Silicon accounts for more than $98 \%$ of the solar cell market [4]. This is primarily because of silicon is earth abundant, highly efficient, and air stable. Crystalline silicon solar cells have achieved efficiencies approaching $25 \%$ in the laboratory and $20 \%$ commercially [5]. Much attention has been drawn on the investigation of solar cells for decades.

A potential candidate for the next generation of solar cells is silicon nanowires (SiNWs) and have already found application as antireflective layers [6] and as active 
elements in organic [7], dye-sensitized [8], quantum-dot sensitized [9], liquid-junction [10, 11], and inorganic solidstate devices [6]. SiNWs are 1D material and there has been interest to incorporate them into photovoltaic cell design due to the wide availability of the material and existing processing infrastructure and direct path for charge transport afforded by the geometry. In addition to that SiNWs have higher absorption capability, nearly $70 \%$, which is much greater than that of bulk silicon [12, 13]. SiNWs show higher absorption since when the SiNW arrays are placed in orthogonal direction to light absorption and charge separation by fabricating radial $\mathrm{p}-\mathrm{n}$ junctions, it enables efficient carrier collection and light trapping in optically thick nanowire arrays, even when minority carrier diffusion lengths are shorter than the optical absorption length [14-16]. SiNWs arrays also show comparatively low reflection losses than planner semiconductor [14] which definitely leads to higher absorption also. The advantage of using nanowires is that, like quantum dots we can tune the band gap to a specific part of the solar spectrum by simply controlling the chemical composition and the coverage density of the wire surface. Significant shrinking of band gap occurs if halogens such as $\mathrm{Cl}, \mathrm{Br}$, and $\mathrm{I}$ are used instead of $\mathrm{H}$ as surface passivation elements without changing the characteristics of semiconductor nanowires [17, 18]. In this paper, we have measured the optical absorption of SiNWs of different dimensions synthesized by electroless metal deposition (EMD) over the range or 200-1,000 $\mathrm{nm}$. Our finding shows that the absorption of SiNWs has greatly modified than that of the bulk silicon.

\section{Methods}

SiNWs array was grown by an aqueous electroless etching method by depositing noble metal nanoparticle like silver and copper. The fabrication process of SiNWs composed of three steps: (1) cleaning of the silicon wafers with ultrasonic bath, (2) electroplating the films of metal nanoparticles onto the cleaned silicon surface, and (3) immersion of the nanoparticle-deposited silicon wafers into HF-based aqueous chemical etching solutions. All the processes were conducted in Teflon lined autoclave.

For silver nanoparticle deposition, the concentration of $\mathrm{AgNO}_{3}$ was $0.02 \mathrm{M}$ with deposition time varied from 60 to $75 \mathrm{~s}$. In case of copper nanoparticle deposition, concentration of $\mathrm{Cu}\left(\mathrm{NO}_{3}\right)_{2}$ was 0.02 and $0.05 \mathrm{M}$ with deposition time varied from 60 to $120 \mathrm{~s}$. In both the cases, concentration of HF was 5.0 M. After the electroless deposition of the silver and copper nanoparticle, the silver/copper metal covered $\mathrm{Si}$ substrate which was confirmed by scanning electron microscopy (SEM). Then, those metal $(\mathrm{Ag} / \mathrm{Cu})$ deposited $\mathrm{Si}$ samples were immersed in an aqueous $\mathrm{HF}$ / $\mathrm{Fe}\left(\mathrm{NO}_{3}\right)_{3}$ solution for etching. The concentration of $\mathrm{HF}$ and $\mathrm{Fe}\left(\mathrm{NO}_{3}\right)_{3}$ was 5 and $0.02 \mathrm{M}$, respectively. Etching was performed at room temperature for 30-75 $\mathrm{min}$ in case of Ag-treated Si samples and 60-120 min for Cu-deposited Si samples. Then after the preparation process, the obtained samples were rinsed copiously in deionized water and dried at room temperature.

Figure 1 shows a schematic picture of top view of SEM image and Fig. 2 shows a schematic picture of side view of SEM image of SiNWs array fabricated on p-type Si substrate. From the SEM micrograph, it has been seen that SiNWs have formed with excellent vertical alignment, uniformity, and packing density, with about $50 \%$ area density. The typical wire diameter from the SEM ranges from 45 to $300 \mathrm{~nm}$ having length from 2 to $4 \mu \mathrm{m}$ long.

Optical absorption spectra were obtained on a UV-1700 spectrophotometer employing halogen lamps, and equipped to measure wavelength range from 200 to $1,000 \mathrm{~nm}$.

The effective absorption (A) in the films was defined as $\mathrm{A}=1-(\mathrm{T}+\mathrm{R})$ without any correction for thin film effects or other possible losses, since comparisons of samples on the same types of transparent substrate were made.

\section{Results and discussion}

The absorption measurement was carried out over a range of wavelengths 200 to $1,000 \mathrm{~nm}$, which covers most of the spectrum that is useful for SiNWs-based solar cells. Figure 3 shows typical total optical absorption spectra of $\mathrm{Cu}-$ treated samples: type-A sample (sample-b, sample-c and sample-d) along with absorption of bulk silicon (sample-a). The absorbance of the solid silicon film shows typical behavior as expected for silicon shown by Run et al. [19]. Here, we have noted that Si film's absorption begin to increase at $400 \mathrm{~nm}$ and remain almost steady up to $1,000 \mathrm{~nm}$ and might be decreased somewhere around $1,100 \mathrm{~nm}$ because of back-reflected loss for long wavelength from top surface [20]. Si absorbs maximum of $47 \%$ of incident radiation, whereas absorption of SiNWs for $\mathrm{Cu}$ treated samples (sample-b, sample-c and sample-d of Fig. 3) was maximum of $78 \%$. For sample-b, etching time was $1 \mathrm{~h}$ and concentration of $\mathrm{Cu}\left(\mathrm{NO}_{3}\right)_{2}$ was $0.05 \mathrm{M}$. Whereas for sample-c and sample-d, treating time was $2 \mathrm{~h}$ with 0.02 and $0.05 \mathrm{M} \mathrm{Cu}\left(\mathrm{NO}_{3}\right)_{2}$.

From the above, we have observed that, absorption of bulk Si film is much smaller than that of SiNWs array over the same wavelength range. This is because by precisely controlling the orientation (vertical vs. slanted), size (nano vs. micro-scale), density and length of SiNWs reflectivity can be reduced. It is also well known that, porous SiNWs 


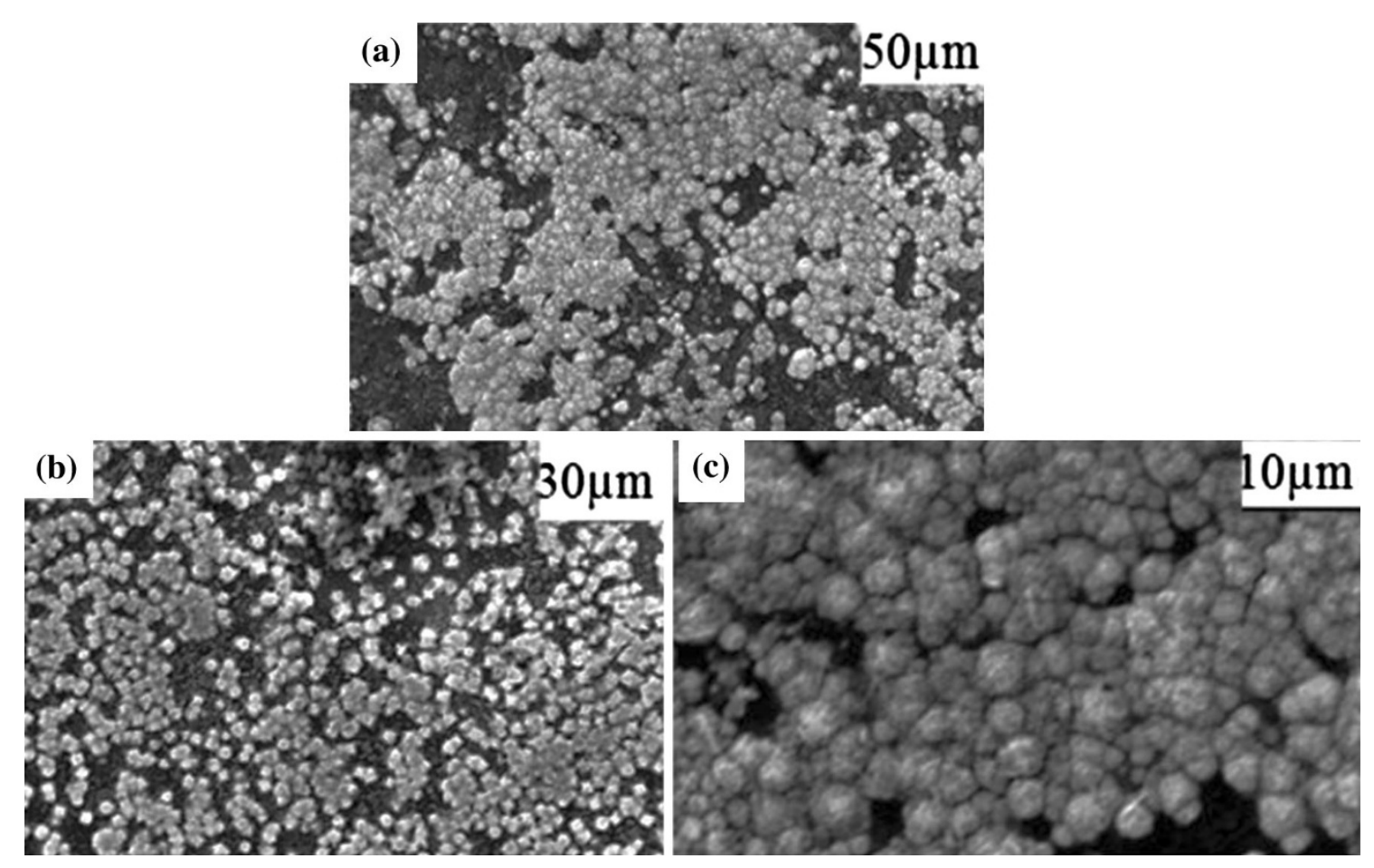

Fig. 1 Top view of SEM image of SiNWs array fabricated on Si substrate
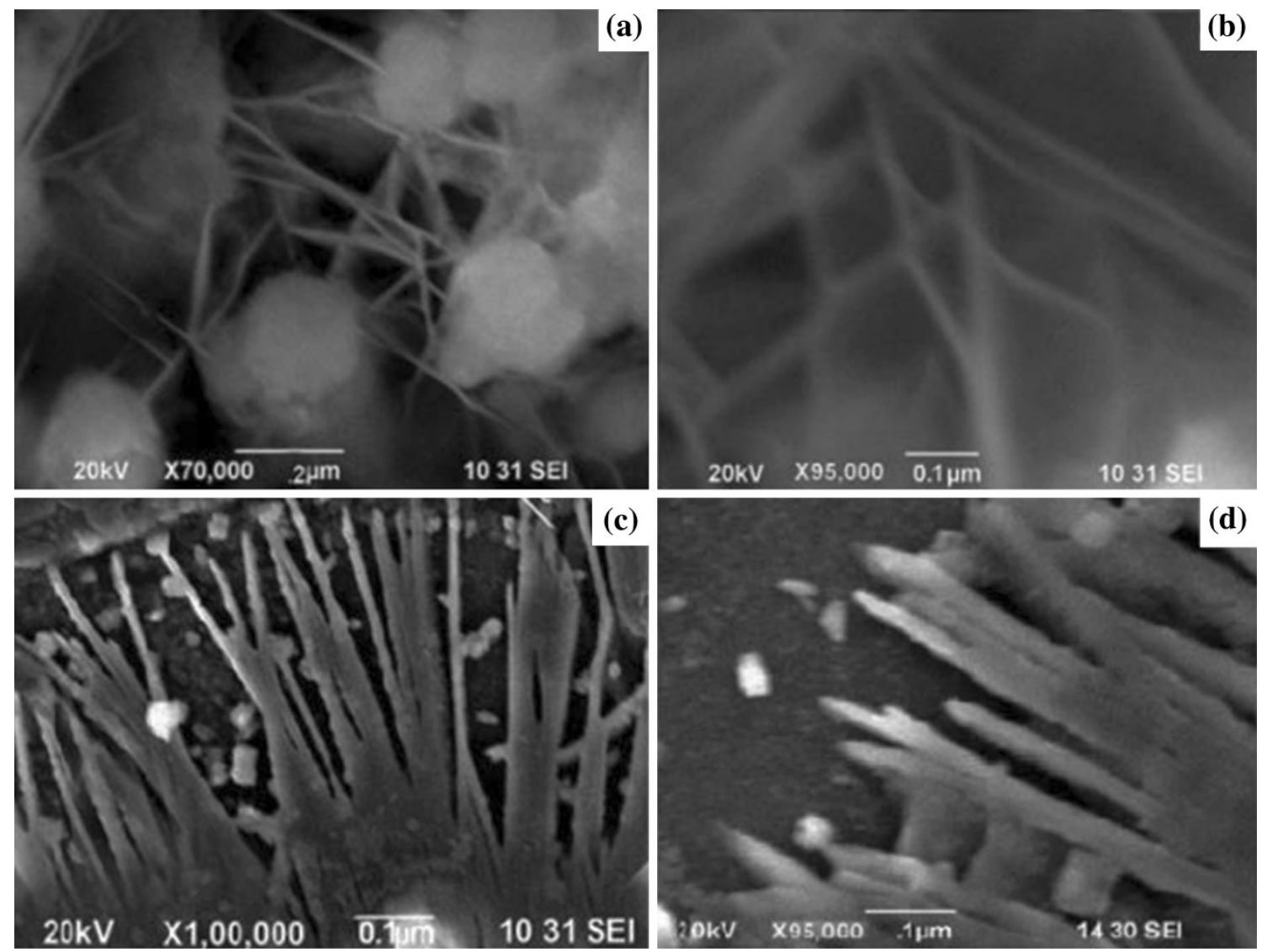

Fig. 2 a, b Side view of Cu synthesized SiNW array and, c, $\mathbf{d}$ Side view of Ag-synthesized SiNW array fabricated on Si substrate 


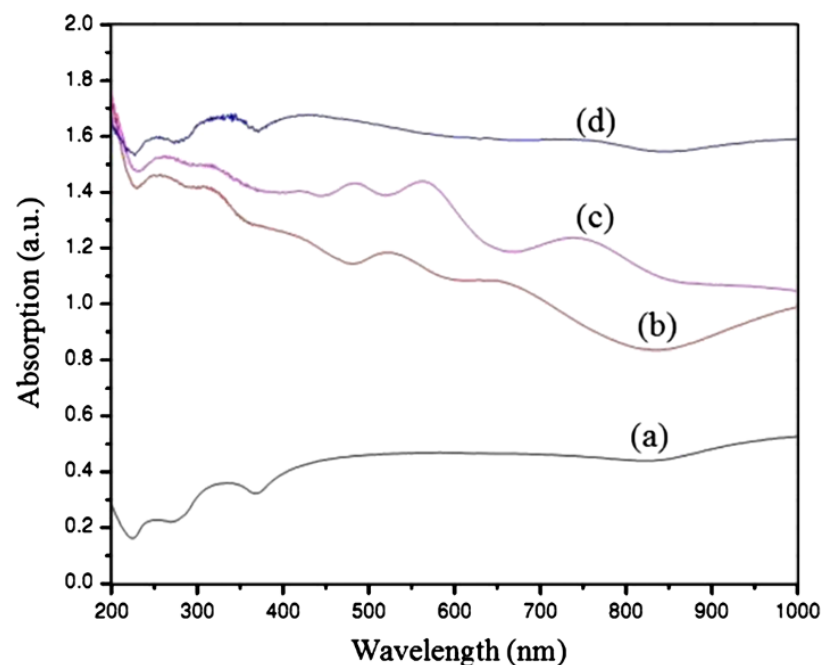

Fig. 3 a Optical absorption spectrum of p-type Si (111) wafer, $b$ Absorption spectrum of nanowires arrays prepared in 5.0 M HF containing $0.02 \mathrm{M} \mathrm{Fe}\left(\mathrm{NO}_{3}\right)_{3}$ and $0.05 \mathrm{M} \mathrm{Cu}\left(\mathrm{NO}_{3}\right)_{2}$ with etching time $1 \mathrm{~h}, c$ Absorption image of $\mathrm{Cu}$-treated nanowires film using $0.02 \mathrm{M}$ $\mathrm{Cu}\left(\mathrm{NO}_{3}\right)_{2}$ with etching time $2 \mathrm{~h}$ and, $d$ Absorbance of nanowires film with etching time $2 \mathrm{~h}$ with $0.05 \mathrm{M} \mathrm{Cu}\left(\mathrm{NO}_{3}\right)_{2}$

can reduce the back reflection up to $5.8 \%$ in the wavelength range of $400-1,000 \mathrm{~nm}$ [6] which leads to higher absorption and therefore can replace other surface-textured microstructure and anti-reflection coatings. At the same time, high aspect ratio nanowires and micropillars enhance absorption through superior light-trapping mechanism, allowing significantly thinner structures and thus reduced material cost. This is especially important for $\mathrm{Si}$ because of the low absorption cross-section inherent to its indirect bandgap, which requires tens to hundreds of times thicker materials for complete absorption compared to direct bandgap material solar cells. The thicker structure also adversely affects carrier extraction due to bulk recombination, especially for less pure low-cost materials. Additionally, high aspect ratio structures allow core-shell radial $\mathrm{p}-\mathrm{n}$ junctions, which effectively lessen the minority carrier collection path to be on the same order of the wire or pillar diameter.

From Fig. 3, it has also been observed that the absorbance of the Cu-deposited SiNWs films increases continually with increasing etching time. The length of the SiNWs films with $2 \mathrm{~h}$ etching was greater than that of the SiNWs synthesized by $1 \mathrm{~h}$ etching time and the diameter decreases with etching time elapse. It has also looked into that with increasing treating time and concentration, higher absorption can be accomplished, may be due to better lighttrapping capability. Therefore, greater quantum confinement of photon occurs and for this reason high absorption achieved. Consequently, we can say that at optimum condition of etching time and density of catalytic metal better findings might be possible.

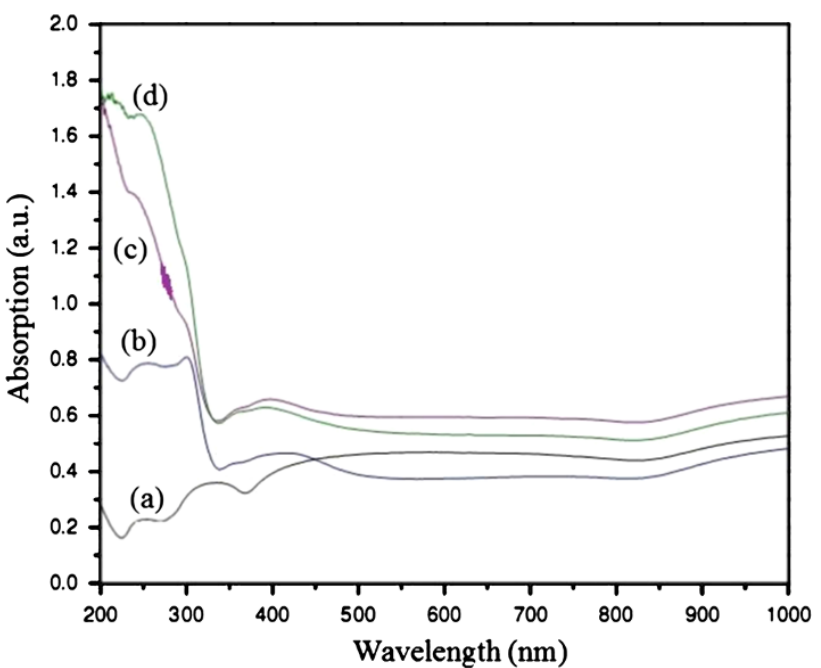

Fig. $4 a$ Optical absorption spectrum of solid Si film. $b$ Absorption of Ag-deposited nanowires film on $\mathrm{Si}$ substrate with etching time 45 min. $c$ Absorption data for Ag-deposited nanowires film on $\mathrm{Si}$ substrate with etching time $45 \mathrm{~min}$ with $0.02 \mathrm{M} \mathrm{AgNO}_{3}$ and, $d$ absorption measurement for Ag-treated $\mathrm{Si}$ substrate with etching time 75 min by means of $0.02 \mathrm{M} \mathrm{AgNO}_{3}$

Absorption measurement was also carried out for $\mathrm{Ag}$ synthesized samples: type-B sample (sample-b, sample-c, and sample-d) with different etching time for same wavelength range of $200-1,000 \mathrm{~nm}$ as shown in Fig. 4. It has been found that, the absorption of sample-b was slightly low for wavelength range of $350-1,000 \mathrm{~nm}$ but absorbance increased to $80 \%$ in the range of $200-350 \mathrm{~nm}$. For sample$\mathrm{c}$ and sample-d, absorption of light energy was greater than the silicon wafer in $350-1,000 \mathrm{~nm}$ but it was increased tremendously up to $83 \%$ in $200-350 \mathrm{~nm}$.

\section{Conclusion}

In conclusion, we have demonstrated that SiNW films possess unique macroscopic optical properties. The nanowires yield significantly increased optical absorption over the full spectrum above the bandgap, as well as reduced transmission and reflectance for wavelengths in case of $\mathrm{Cu}$ deposited SiNWs, whereas for Ag-deposited SiNWs, absorbance was maximum $83 \%$ which is much greater than that of the bulk silicon as they absorbed maximum $43 \%$ of the radiation. This inspection facilitates that the synthesized nanostructure could be a potential contender for efficient PV solar cell.

Acknowledgements Author's would like to thank Mr. Mahbubul Haq, Director of the Institute of Electronics, Atomic Energy Research Establishment (AERE), Savar, for providing with the Silicon wafer from the project on "Center of Excellence for the Development of Very Large Scale Integration (VLSI) Technology in Bangladesh" supported by Government of the Peoples Republic of Bangladesh, and 
to Mrs. Rumana Islam, project fellow in Centre for Advance Research in Science (CARS), University of Dhaka, for her help to work with UV spectrophotometer.

Conflict of interest The authors declare that they have no competing interests.

Author's contributions The authors clearly proclaim that all the authors have equal contribution on this paper

Open Access This article is distributed under the terms of the Creative Commons Attribution License which permits any use, distribution, and reproduction in any medium, provided the original author(s) and the source are credited.

\section{References}

1. Shah, A., Torres, P., Tscharner, R., Wyrsch, N., Keppner, H.: Photovoltaic technology: the case for thin-film solar cells. Science 285(5428), 692-698 (1999)

2. Green AM (2006) Recent developments and future prospects for third generation and other advanced cells. Conference record of the 2006 IEEE 4th world conference on photovoltaic energy conversion, vol 1. pp 15-19

3. Chapin, D.M., Fuller, C.S., Pearson, G.S.: A new silicon p-n junction photocell for converting solar radiation into electrical power. J. Appl. Phys. 25, 676 (1954)

4. Ginley, D., Green, M.A., Collins, R.: Solar energy conversion towards 1 terawatt. MRS Bull. 33(2), 355-364 (2008)

5. Green, M.A., Emery, K., Hishikawa, Y., Warta, W.: Solar cell efficiency tables (version 35). Prog. Photovolt. 18, 144-150 (2010)

6. Peng, K., Xu, Y., Wu, Y., Yan, Y., Lee, S.T., Zhu, J.: Aligned single-crystalline $\mathrm{Si}$ nanowire arrays for photovoltaic applications. Small 1, 1062-1067 (2005)

7. Hu, L., Chen, G.: Analysis of optical absorption in silicon nanowire arrays for photovoltaic applications. Nano. Lett. 7, 3249-3252 (2007)

8. Law, M., Greene, L.E., Johnson, J.C., Saykally, R., Yang, P.D.: Nanowire dye-sensitized solar cells. Nat. Mater. 4, 455-459 (2005)
9. Leschkies, K.S., Divakar, R., Basu, J., Enache-Pommer, E., Boercker, J.E., Carter, C.B., Kortshagen, U.R., Norris, D.J., Aydil, E.S.: Photosensitization of $\mathrm{ZnO}$ nanowires with CdSe quantum dots for photovoltaic devices. Nano. Lett. 7, 1793-1798 (2007)

10. Maiolo, J.R., Kayes, B.M., Filler, M.A., Putnam, M.C., Kelzenberg, M.D., Atwater, H.A., Lewis, N.S.: High aspect ratio silicon wire array photo electrochemical cells. J. Am. Chem. Soc. 129(41), 12346-12347 (2007)

11. Goodey, A.P., Eichfeld, S.M., Lew, K.K., Redwing, J.M., Mallouk, T.E.: Silicon nanowire array photoelectrochemical cells. J. Am. Chem. Soc. 129(41), 12344-12345 (2007)

12. Jia, Z., Zongfu, Y., Burkhard, G.F., Ching-Mei, H., Stephen, T.C.: Optical absorption enhancement in amorphous silicon nanowire and nanocone arrays. Nano. Lett. 9(1), 279-282 (2009)

13. Kelzenberg, M.D., Boettcher, S.W., Petykiewicz, J.A., TurnerEvans, D.B.: Enhanced absorption in silicon nanocone arrays for photovoltaics. Nat. Mater. 9(3), 239 (2010)

14. Garnett, E., Yang, P.: Light trapping in silicon nanowire solar cells. Nano. Lett. 10(3), 1082-1087 (2010)

15. Xie, W.Q., Oh, J.I., Shen, W.Z.: Realization of effective light trapping and omnidirectional antireflection in smooth surface silicon nanowire arrays. Nanotechnology 22, 065704 (2011)

16. Liu, W.F., Oh, J.I., Shen, W.Z.: Light trapping in single coaxial nanowires for photovoltaic applications. IEEE 32(1), 5-47 (2011)

17. Conibeer, G., Green, M., Cho, E.C., Knig, D., Cho, Y.H., Fangsuwannarak, T., Scardera, G., Pink, E., Huang, Y., Puzzer, T., Huang, S., Song, D., Flynn, C., Park, S., Hao, X., Mansfield, D.: Silicon quantum dot nanostructures for tandem photovoltaic cells. Thin Solid Films 516(20), 6748-6756 (2008)

18. Leu, P.W., Shan, B., Cho, K.: Surface chemical control of the electronic structure of silicon nanowires: density functional calculations. Phys. Rev. B. 73(19), 195320-195324 (2006)

19. Long, R., English, J.N.: Band gap engineering of (N, Si)-codoped $\mathrm{TiO}_{2}$ from hybrid density functional theory calculations. New. J. Phys. 14, 053007 (2012)

20. Tsakalakos, L., Balch, J., Fronheiser, J., Shih, M.Y., LeBoeuf, S.F.: Strong broadband optical absorption in silicon nanowire films. J. Nanophotonics 1, 013552 (2007) 